\title{
Luchas urbanas en barrios populares de la ciudad de Quito: territorialidad e historicidad desde las voces de sus protagonistas
}

\author{
Urban struggles in popular neighborhoods of the \\ city of Quito: territoriality and historicity from the \\ voices of its protagonists
}

\section{Lutas urbanas em bairros populares da cidade de Quito: territorialidade e historicidade desde as falas dos seus protagonistas}

\author{
Marcelo Rodríguez-Mancilla \\ Universidad Federal de Río de Janeiro, Brasil \\ Gino Grondona-Opazo \\ Universidad Politécnica Salesiana, Ecuador
}

Autor referente: ggrondona@ups.edu.ec

Historia Editorial

Recibido: 31/05/2017

Aceptado: 09/03/2018

\section{RESUMEN}

En la literatura psicosocial desarrollada en América Latina se ha venido configurando un debate reflexivo hacia dentro y hacia fuera, en torno a las tensiones conceptuales, sentidos y formas institucionalizadas de las praxis comunitarias, que han sido fundamentadas por la Psicología Social Comunitaria (PSC) a la luz de los problemas sociales contemporáneos. El presente estudio, situado en este marco, se propuso comprender las luchas populares por-el-lugar, a partir de los factores psicosociales que median la 
construcción de territorialidad e historicidad, en la producción social del hábitat popular en la periferia urbana de Quito. Para esto, se aplicaron 33 entrevistas cualitativas a mujeres y hombres dirigentes sociales de 30 barrios populares. A través de esta aproximación exploratoria al proceso de lucha popular, logramos identificar ciertas limitaciones conceptuales de la categoría de "comunidad" ampliamente utilizada en PSC. A su vez, reflexionamos sobre la potencial ampliación de los marcos comprensivos de las categorías: historicidad y territorialidad. Concluimos que hay un déficit teórico importante en la disciplina, la que se construye principalmente a partir de categorías descriptivas tendientes a la homogenización de los fenómenos. Esta cuestión supone el desafío de revitalizar el corpus de conocimientos existentes en la región, y capturar la diversidad y complejidad de formas de apropiación social y territorial a escala barrial.

Palabras clave: Psicología social comunitaria; Hábitat popular; Historicidad; Territorialidad

\section{ABSTRACT}

In the psychosocial literature developed in Latin America, a reflexive debate has been taking place both inward and outward, around the conceptual tensions, meanings and institutionalized forms of community praxis, which have been supported by Community Social Psychology (PSC) at the light of contemporary social problems. The present study, based on this framework, sought to understand the popular struggles for-the-place, based on the psychosocial factors that mediate the construction of territoriality and historicity, in the social production of the popular habitat in the urban periphery of Quito. For this, 33 qualitative interviews were applied to social leaders, women and men of 30 popular neighborhoods.
Through this exploratory approach to the process of popular struggle, we managed to identify certain conceptual limitations of the category of "community" widely used in PSC. At the same time, we reflect on the potential extension of the comprehensive frameworks of the categories: historicity and territoriality. We conclude that there is an important theoretical deficit in the discipline, which is constructed mainly from descriptive categories tending to the homogenization of the phenomena. This supposes the challenge of revitalizing the corpus of existing knowledge in the region, and capturing the diversity and complexity of forms of social and territorial appropriation on a neighborhood scale.

Keywords: Community social psychology; Popular habitat; Historicity; Territoriality

\section{RESUMO}

$\mathrm{Na}$ literatura psicossocial desenvolvida na América Latina tem vindo configurando um debate reflexivo para dentro e para fora, ao redor à tensões conceituais, sentidos e formas institucionalizadas das práxis comunitárias que tinham sido fundamentadas pela Psicologia Social Comunitária (PSC), à luz dos problemas sociais contemporâneos. A seguinte pesquisa, situada neste contexto, se propus compreender as lutas populares 
pelo-lugar, a partir dos fatores psicossociais me mediam a construção de territorialidade e historicidade, na produção social do habitat popular na periferia urbana de Quito. Para isto, se aplicaram 33 entrevistas qualitativas a mulheres e homens lideranças sociais de 30 bairros populares. Através de essa aproximação exploratória do processo de luta popular, lograrmos identificar certos limites conceituais da categoria "comunidade" amplamente utilizada em PSC. Mesmo assim, refletirmos sobre a potencial ampliação dos marcos compreensivos das categorias: historicidade e territorialidade. Concluirmos que há um déficit teórico importante na disciplina, a qual se constrói principalmente a partir de categorias descritivas tendentes à homogeneização dos fenômenos. Essa questão supõe o desafio de revitalizar os corpus de conhecimentos existentes na região, e captar a diversidade e complexidade de formas de apropriação social e territorial na escala do bairro.

Palavras chave: Psicologia social comunitária; Habitat popular; Comunidade; Historicidade; Territorialidade

\section{Introducción}

os procesos de urbanización, (des)industrialización y modernización, que se han venido consolidando en América Latina, inciden en la reconfiguración de los lazos sociales y en los cambios de los patrones de sociabilidad (Jariego, 2004; Lefebvre, 1976). Estos procesos se desarrollan en un contexto de creciente desigualdad social, de predominio del individualismo por sobre los valores colectivos y solidarios (Rodríguez, 2012), y de consolidación de un modelo de desarrollo socio-económico neoliberal. Estos cambios sociopolíticos, económicos y las tendencias a la fragmentación socio-territorial y la exclusión social (Rodríguez, 2013), colocan importantes desafíos teórico-conceptuales para el quehacer de la Psicología Social Comunitaria (PSC).

En la literatura psicosocial se explicita la necesidad de revisión crítica de: a) los principales conceptos y fundamentos que sustentan la disciplina (Rodríguez y Montenegro, 2016; Wiesenfeld. 2016; Almeida y Sánchez, 2014); b) las tensiones entre la praxis comunitaria y las políticas públicas (Berroeta, 2014; Rodríguez, 2012; Winkler, Alvear, Olivares, \& Pasmanik, 2009), c) la posibilidad de articulación conceptual entre la psicología social comunitaria y la psicología ambiental (Wiesenfeld, 1994); y d) la 
necesidad de situar las reflexiones en el contexto de las luchas sociales, la interculturalidad, y la incorporación de la historicidad y la territorialidad como dimensiones articuladoras de la existencia humana (Grondona-Opazo y Rodríguez, 2017).

Dentro de este orden de ideas, esta investigación se propuso comprender las luchas populares por-el-lugar, a partir de los factores psicosociales que median la construcción de territorialidad e historicidad en la producción social del hábitat popular, para problematizar el concepto de "comunidad" usado comúnmente por la PSC.

\section{Comunidad, subjetividad y lucha por-el-lugar}

La comunidad, en tanto proceso de construcción de la subjetividad colectiva, es el espacio sobre el cual se erige la reflexión y acción de la PSC. Esta disciplina centra su objeto de estudio en los factores psicosociales que median la construcción de comunidades y que ejercen su poder para buscar cambios en el entorno y en la estructura social (Montero, 2004; Musitu, Herrera, Cantera, \& Montenegro, 2004). Sánchez Vidal (2009) identifica algunas dimensiones comunes a las diferentes definiciones de la "comunidad" tales como: un territorio compartido, la existencia de lazos emocionales, relaciones simbólicas, la interacción social, la interdependencia, y el sentido de comunidad.

Montero conceptualiza la comunidad como "un grupo en constante transformación y evolución (su tamaño puede variar), que en su interrelación genera un sentido de pertenencia e identidad social, tomando sus integrantes conciencia de sí como grupo, y fortaleciéndose como unidad y potencialidad social" (Montero, 2004, p. 100). Almeida \& Sánchez (2014) proponen que hay que considerar elementos estructurales y psicosociales para comprender los procesos de reconfiguración de lazos comunitarios y de conceptualización de comunidad/sociedad. Interacción, conflicto y utopía son estos ejes articuladores. De ahí que la comunidad es entendida como "un proceso social 
constituido por personas y grupos en el que la interacción, el conflicto y la utopía se articulan de manera diferenciada, consciente e inconsciente, de forma más o menos alienante o liberadora" (Almeida \& Sánchez, 2014, p. 253).

Otras propuestas han planteado la des-territorialización del propio concepto de comunidad (Krause, 2001). La pertenencia (sentirse parte de, sentir que se comparten valores o propósitos), la interrelación (existencia de comunicación e interdependencia) y la cultura común (significados compartidos y una visión común de la vida); serían las dimensiones constitutivas del concepto de comunidad.

En general, el concepto de comunidad tiende a definirse desde el plano de las relaciones y vínculos sociales. El territorio es considerado como un mero escenario donde tales relaciones se desenvuelven. No pasa a concebirse como una dimensión central en los procesos de construcción de las comunidades. Esto plantea la necesidad de considerar las relaciones entre los conceptos de territorialidad, historicidad, subjetividad y comunidad. El espacio privilegiado para esto es el análisis de las luchas sociales, en donde los grupos se constituyen como una potencialidad social que ejerce su poder.

Las formas de lucha en América Latina se caracterizan por lo heterogéneo, lo territorial y lo popular (Porto-Gonçalves, 2009; Zibechi, 2007). Una de las principales características de las luchas sociales en América Latina es, justamente, su territorialización. Proceso que está asociado al arraigo en espacios físicos recuperados o conquistados. Las nuevas características de estas luchas, dicen relación con: la reubicación de los sectores populares en las periferias urbanas; la búsqueda de autonomía tanto del Estado como de los partidos políticos; la revalorización y afirmación de la cultura e identidad del pueblo; un nuevo rol protagónico de las mujeres; la dinámica de organización del trabajo y su relación con la naturaleza, a partir de formas auto-organizativas de reproducción de la vida familiar y comunitaria, y acciones principalmente de auto-afirmación (Zibechi, 2003). 
El territorio, a su vez, se constituye en significante de identidad, tanto personal como colectivo, dando cuenta de su dimensión histórica y a la vez política, en el entendido que "la identidad no es generada porque se comparte un territorio común, sino que es la identidad la que genera, instaura, el territorio" (Segato, 2007, p. 87). En otras palabras, "el territorio es el espacio en el que se construye colectivamente una nueva organización social, donde los nuevos sujetos se instituyen, instituyendo su espacio, apropiándoselo material y simbólicamente" (Zibechi, 2003, p. 187). Es en este sentido que el lugar puede entenderse como el territorio construido por las comunidades. Las luchas, por tanto, se despliegan en torno a la defensa de un territorio-lugar, en sus dimensiones económicas, culturales, sociales y/o ambientales (Toro, 2012).

Las luchas sociales de base territorial activan complejos procesos de construcción de subjetividades políticas. Zemelman (2012) sostiene que el ser humano para ser sujeto, debe conquistar su libertad en el marco del desarrollo histórico en el cual está inmerso. Pero esta libertad contiene la tensión de ser, simultáneamente, un producto histórico y una fuerza que transforma (o tiende a transformar) las condiciones históricas.

Es en la realidad social donde "la subjetividad articula dimensiones como la memoria, la cultura, la conciencia, la voluntad y la utopía, las cuales expresan la apropiación de la historicidad social, a la vez que le confieren sentido y animan su potencialidad" (González, Aguilera \& Torres, 2013, p. 53). La construcción de subjetividades políticas no se reduce a la participación en las instituciones sociales o al reclamo del ciudadano. Es más bien una potencia, en el sentido de que se expresa en vínculos, prácticas y articulaciones sociales, así como en la construcción de visiones de futuro (González, Aguilera \& Torres, 2013).

Retamozo (2006) propone una tríada conceptual compuesta por el sujeto social, el movimiento social y la subjetividad colectiva, para comprender el devenir de los sujetos sociales. Los sujetos sociales portan una historicidad y un universo simbólico, y con base 
a una voluntad colectiva se articulan en movimientos sociales, construyendo demandas sociales, realizando formas de acción colectiva y elaborando perspectivas de futuro. A partir de lo anterior, la subjetividad colectiva es pensada como un proceso de dotar de sentido a situaciones compartidas a partir de movilizar códigos que pueden provenir de diferentes campos (cognitivo, emotivo, ético, estético).

Ahora bien, proponemos problematizar el concepto de comunidad en su relación con la idea de territorialidad e historicidad y la construcción de subjetividades políticas en procesos de lucha por-el-lugar. En primer lugar, conceptualizamos la territorialidad como un proceso en el cual los sectores populares, por medio de una acción colectiva, ejercen un poder sobre el territorio, produciendo y transformando dicho territorio en su lugar. Al mismo tiempo, se apropian simbólicamente de dicho lugar y generan las condiciones para su reproducción social; es decir, se produce una nueva territorialidad, a partir de la apropiación e identificación simbólica del territorio-lugar, al mismo tiempo que se reproducen socialmente como pueblo.

En segundo lugar, la idea de historicidad la entendemos como un proceso en el cual los sectores populares, por medio de la acción colectiva, desarrollan una praxis de lucha popular en estas periferias, que genera las condiciones para la emergencia de un proceso de subjetivación política que les constituye como 'pueblo'. En otras palabras, es a partir de la praxis de lucha popular que los sectores populares (dispersos y fragmentados), se constituyen en sujeto colectivo y luchan por sus reivindicaciones históricas.

\section{Metodología}

La metodología de investigación se centró en las experiencias de las personas, en tanto procesos, comportamientos, efectos y acciones, con el fin de reconstruir la producción de 
sentidos y significados que organizaron sus luchas. El estudio fue de tipo exploratoriodescriptivo, por ser una aproximación inicial al campo de análisis propuesto,

Se definió la muestra con criterios específicos relacionados al objetivo central del estudio. Los criterios fueron: a) ser hombre o mujer mayor de edad y de nacionalidad ecuatoriana, b) ser residente histórico del barrio que es reportado, c) haber participado activamente como dirigente social en el proceso de producción social del barrio y de lucha por-el-lugar. Se analizó una muestra de 33 entrevistas transcritas de dirigentes sociales, de los cuales 15 fueron reportadas por hombres y 18 por mujeres. La muestra se distribuyó en los 30 barrios populares ubicados en la periferia de Quito.

La técnica de producción de información fue la entrevista semi-estructurada. Las subdimensiones consultadas fueron: aspectos e hitos históricos en la producción de los barrios, sentido y acción colectiva de la organización, estrategias impulsadas y conflictos centrales, potencialidades y limitaciones del proceso, y aspectos afectivos. Estas entrevistas fueron aplicadas, entre junio y diciembre del año 2015, por estudiantes de psicología de la Universidad Politécnica Salesiana que se capacitaron previamente. Las y los entrevistados firmaron voluntariamente un consentimiento informado para poder participar en el estudio. Los dirigentes fueron contactados a partir de un proceso de acompañamiento previo al desarrollo de actividades de organizaciones sociales vinculadas a la lucha por el derecho a la vivienda y la ciudad. En este proceso conocimos a dirigentes que participaron en el Contrato Social por la Vivienda, que fue un colectivo de diversas organizaciones que incidieron políticamente en el proceso constituyente vivido entre los años 2007 y 2008 en Ecuador (Rodríguez, Grondona-Opazo, Erazo \& Festjens, 2016).

Para el procesamiento analítico de los datos se realizó un análisis de contenido de tipo semántico y categorial, con base en las sub-dimensiones predefinidas. Se identificaron las 
unidades de análisis y de contexto por cada entrevista aplicada, con el propósito de identificar los diversos tópicos que emergieron de las experiencias reportadas. Luego de esto, se realizó el proceso de categorización con base en el agrupamiento de los tópicos, que dieron cuenta de la multidimensionalidad del proceso de lucha por-el-lugar. Posteriormente se identificaron los principales factores psicosociales que mediaron la construcción de territorialidad e historicidad, para finalmente proponer algunas reflexiones y discusiones en torno al concepto de comunidad.

\section{Análisis Descriptivo de Resultados: Voces de las y los protagonistas}

Pasamos a exponer los resultados que describen las características, significados, afectos y sentidos del proceso de lucha desde las voces de sus protagonistas.

\section{Procesos de construcción del barrio}

La trayectorias a partir de las cuales se disputa el suelo urbano y urbanizables por parte de los sectores populares, no es una realidad homogénea. Si bien la orientación de la acción es hacia el ejercicio del derecho a la vivienda y a la posibilidad de contar con un lugar para vivir, las estrategias y procesos de lucha se van diferenciando según el contexto sociopolítico. Los procesos de construcción del barrio están motivados principalmente por la necesidad de infraestructura física que le da sostenimiento a la forma de vida barrial, pero bajo complejas condiciones de precariedad económica y educativa, y de exclusión social y política.

La característica central de la conformación social de los barrios populares es que son el resultado de la agrupación de muchas personas provenientes de diferentes latitudes del Ecuador. Se van constituyendo territorios de la diversidad cultural, en donde cada migrante se reconoce con los otros en base a la necesidad común, y la necesidad al mismo tiempo de reconocerse en sus diferentes historias y trayectorias de vida. 
También se presentaron formas de organización social cuya motivación central era salir de la situación del inquilinato (del arrendamiento), para lo cual se generaban importantes convocatorias de familias y así poder acceder a la compra de terrenos disponibles en la ciudad.

El acceso a infraestructura comunitaria y espacios de socialización ha sido trabajado comunitariamente en la mayoría de los casos. El acceso a salud y educación está condicionado por la localización y acceso económico a tales servicios, lo que genera una percepción de discriminación por las dificultades de acceso. A su vez, aparecen demandas sociales graduales para acceder a políticas culturales, educativas y servicios municipales que favorezcan la condición de vida de niños, niñas, jóvenes y adultos mayores. Las canchas de fútbol, el adoquinado de calles, la casa barrial, plazas, cetros de salud y educación, la conectividad vial y de transporte, guarderías, conectividad de teléfono e internet, son los servicios y equipamientos que más se valoran como necesarios para mejorar las condiciones de vida de las y los habitantes.

Ahorita ya estamos bien instalados vea (...) acá afuera tenemos ese subcentro de salud, más arribita tenemos el jardín, por acá abajo tenemos lo que es la cancha, que el Municipio aun nos debe un tramo de la Casa Barrial, aquicito es la escuela y ahorita está funcionando también los 60 y piquito, también en la actualidad estamos pidiendo que nos den un comedor (Dirigente Barrio La Pulida, comunicación personal, 15 de junio del 2015).

\section{Sentido colectivo de la organización}

Bajo condiciones tan adversas de pobreza, de tener que organizar a personas de diferentes lugares y orígenes, el rol de las y los dirigentes es central, pues en ellos se encarnan diversas formas de gestión y motivaciones que permiten llevar adelante procesos de construcción de comunidad y del hábitat popular. 
Ante las necesidades de diversos órdenes que se refieren como impulsores de la acción de la dirigencia, se presenta la necesidad de organización como algo fundamental para resolver los problemas de las familias. La confianza, la solidaridad, la unidad, la exigibilidad de los derechos, y la autogestión; permite avanzar con las reivindicaciones, y responder organizadamente a las injusticias sociales y la pobreza existentes.

La necesidad, al menos mi calle la más olvidada, que como estamos prácticamente a la quebrada, no teníamos prácticamente es nada, olvidados por entero. Nadie alzaba un dedo por nosotros, entonces era empedrado, era una cosa terrible, entonces yo indignada de que no hacían nada y gente que uuuh ni se les conocía, entonces yo... y no que yo fui para que yo sea electa, jno! Fui a protestar (Dirigente Barrio Bellavista, comunicación personal, 25 de julio del 2015). La organización es lo importante en una sociedad, de una comunidad partiendo desde nuestra familia, primeramente debe haber una organización, respeto, consideración para poder surgir (Dirigente Barrio San Ignacio, comunicación personal, 14 de agosto del 2015)

Las necesidades son múltiples y de diversos órdenes. Una de las centrales es la necesidad de producir la vivienda y el barrio con condiciones propicias. Esto refiere a obras de servicios básicos e infraestructura comunitaria, a la seguridad familiar y del espacio público comunitario, a generar espacios de encuentro, socialización y desarrollo de actividades deportivas y recreativas en el barrio. Todo lo cual requiere de una fuerte valoración a la organización social, como la vía necesaria para avanzar progresivamente en la reivindicación de derechos sociales y la dignificación de los horizontes de vida.

El derecho a la vivienda, segundo al resto de derechos, porque les decíamos y hemos dicho siempre a los compañeros a ver, el derecho a la vivienda es uno, 
fundamental, pero hay montón de derechos que hay que pelear, y si alguna vez nosotros tenemos cumplidos todos esos derechos hay que ayudar a que el resto de la población en nuestro país y en el mundo se cumpla con esos derechos (Dirigente Barrio San Juan Bosco de Quito del Itchimbía, comunicación personal, 12 de noviembre del 2015).

\section{Conflictos y limitaciones}

Estos horizontes de sentido se afectan permanentemente por la conflictividad que viven las dinámicas barriales. Los conflictos se dan tanto a nivel interno, de relaciones con otras organizaciones, y a nivel de externo en las relaciones con las lógicas institucionales que se imponen por el Estado y el gobierno de la ciudad.

A nivel interno de la organización, las dificultades centrales se dieron por la falta de experiencia de algunas y algunos dirigentes, relación machista y mal intencionada, discontinuidad de las relaciones solidarias, y problemas para resolver las discrepancias entre participantes de las organizaciones que generan ciertas divisiones.

Es ese conflicto interno que normalmente tenemos las organizaciones porque donde haya una organización compuesta por más de diez personas ya viene la discrepancia, ese conflicto interno es el que no nos permite avanzar (Dirigente Barrio Puertas del Sol, comunicación personal, 25 de octubre del 2015).

La violencia por las disputas de tierras también aconteció, en donde el rol de los traficantes fue precisamente adueñarse de las tierras y venderlas sin respaldo jurídico. Esto generó el problema de no poder legalizar los títulos de dominio de las tierras. A su vez, las disputas por la tierra generaron muertes entre las personas que luchaban por lo mismo.

Aquí la primera pelea que hubo..., hasta hubo un muerto o sea pero entre prácticamente entre la gente peleando porque teníamos un tanquero de agua..., o 
sea el municipio nos dio un carro grandote y teníamos que dar el mantenimiento, ahí si había gente, ahí si había dirigentes que querían ocupar el barrio por lucro, por ahí amenazo a otro dirigente que te mato y a los ocho días se murió de un tiro pero no se supo quién era (Dirigente Barrio La Pulida, comunicación personal, 15 de junio del 2015).

Los conflictos con la institucionalidad se han dado por decisiones autoritarias, por el ejercicio de la violencia del Estado a partir de intentos de desalojo: y por incumplimiento de promesas hechas por funcionarios estatales. Todo esto genera un sentimiento de desconfianza por el engaño, la violencia y la manipulación.

Era que nosotros siempre estábamos en permanente zozobra por el tema del desalojo. Entonces para eso tuvimos que enfrentar, tuvimos que armar las guardias comunitarias permanentes (Dirigente Barrio San Juan Bosco de Quito del Itchimbía, comunicación personal, 12 de noviembre del 2015).

La dimensión de conflictos y antagonismos limitan la acción comunitaria, y afectan los procesos de reivindicación de derechos. Se destacan cuestiones relacionadas con el predominio del egoísmo e interés personal de algunas personas en las organizaciones. Es difícil, según se indica, mantener una cierta continuidad en la unión de las personas, la colaboración y participación, lo que se evidencia en una percepción de desorganización. Dado que en muchos barrios también han existido dirigencias negativas para la comunidad, se desarrolla una cierta desconfianza con respecto a las gestiones.

Es tan difícil unir a la gente, es tan difícil... ¿sabe cuándo? ...cuando no hay obras, o sea cuando ya todos tienen, es bien difícil decir vengan a una sesión, es bien difícil. Pero en cambio todavía tengo muchas, muchas necesidades por cubrirlas todavía (Dirigente Barrio Bellavista, comunicación personal, 25 de julio del 2015). 


\section{Estrategias, potencialidades y afectividades}

Ante tales problemas y conflictos de carácter internos y externos, las y los dirigentes crean estrategias para fortalecer sus organizaciones, construir sentido de comunidad y avanzar con el proceso histórico de apropiación del territorio. Un tema central es el proceso de aprendizaje y concientización que se requieren para clarificar y comprender las situaciones en que se van generando los conflictos. Se apela a la participación, a la comunicación permanente y fluida para informar y expresar ideas. Con esto se construyen relaciones empáticas, de entendimiento entre las personas de la comunidad. Se cuida mucho el tema de la transparencia de los procesos, apelando al valor de la honestidad como central y en donde el sentido de la necesidad de la mayoría debe primar.

La misma experiencia de vida diaria de comunidad, yo creo que nos ha dado muchas estrategias, el hecho de encontrarnos caminando juntos los vecinos, es un tema de una comunicación directa en donde podemos contar lo que se está haciendo, contar de nuestros proyectos que tenemos, otra de las formas también ha sido a través de la forma escrita de una comunicación escrita (Dirigente Barrio Osorio, comunicación personal, 30 de agosto del 2015).

Crear espacios para la formación y capacitación, tanto para dirigentes sociales como para socios y socias de las organizaciones, es central. Se realizan actividades para el desarrollo de las familias, especialmente niños, niñas y jóvenes, a partir de lo cual se va constituyendo tanto el sentido colectivo de la organización, como la conciencia de que es muy importante superar el individualismo imperante y de potenciar la participación.

La mayoría de las y los dirigentes señalan que las potencialidades están en la construcción cotidiana de la lucha, en la consolidación de relaciones sociales que se justifiquen en valores humanos tales como: la voluntad de servir a la comunidad, de tener un sentido colectivo, de ayuda mutua, el deseo de superación, el respeto entre las 
personas, incluso al más humilde, la confianza en la organización; y las relaciones solidarias entre socios y socias. La propia actitud personal y colectiva de "estar en lucha" es una potencialidad. En este sentido se define un ser humano digno, en la búsqueda de dignidad y justicia, y que participa comprometidamente para lograrlo.

La principalidad potencialidad que yo creo es la dignidad. Cuando nosotros les hacemos entender a los compañeros que son seres humanos que tienen dignidad, que tienen derechos ellos dieron un salto cualitativo increíble, es decir se metieron a la lucha para morir o para vivir (Dirigente Barrio San Juan Bosco de Quito del Itchimbía, comunicación personal, 12 de noviembre del 2015).

En el proceso se reportan sentimientos de felicidad, orgullo, emoción positiva, cuando se logran los objetivos de la lucha y cuando se reconoce el esfuerzo y trabajo que realizan. Sobre todo cuando existe la autogestión, y el trabajo comunitario, colectivo para construir el barrio. La lucha se nutre de los logros y estos producen sensaciones de realización personal, familiar y colectiva.

Muchas satisfacciones, primeramente de ver a las familias de escasos recursos, ser propietarios de su vivienda, segundo, mantener a la juventud unida en el marco del deporte, tercero tener una escuela fiscal, donde los niños pues ya no tenían que sufrir la escases del transporte, sino tenían su escuela ahí, en el sector del barrio, espacios verdes para que el resto de niños puedan disfrutar (Dirigente Barrio Caminos a la Libertad, comunicación personal, 09 de diciembre del 2015).

Los momentos que se reconocen como más significativos en la lucha, refieren al reconocimiento jurídico por parte de las instituciones públicas, a los logros asociados al proceso de ocupación de tierras y al proceso general de producción del hábitat popular, en donde las mujeres cumplen un rol central. 
Para mí la satisfacción más grande fue cuando los compañeros.... Uno primero el sorteo de las viviendas bueno cuando nos entregaron la escritura fue el primero de las grandes emociones que nos entregaron las escrituras del municipio luego cuando ya hicimos el sorteo de las viviendas y luego cuando las entregamos. Fue como un deber cumplido (Dirigente Barrio Cajamar, comunicación personal, 27 de junio del 2015).

\section{Factores psicosociales que median la construcción de territorialidad e historicidad}

A partir de los resultados descritos, identificamos algunos elementos que nos permitirán aportar a la comprensión de los factores psicosociales que median la construcción de territorialidad e historicidad en las luchas urbano-populares.

En relación con la territorialidad, se puede observar cómo la acción colectiva está orientada principalmente hacia el ejercicio efectivo del derecho a la vivienda, por medio de la conformación de figuras jurídicas que permiten una acción directa en torno a este derecho, como las cooperativas de vivienda; y en este sentido, los procesos han sido motivados principalmente por la necesidad de obras de infraestructura física y por el acceso a servicios sociales fundamentales para dar sostenimiento a la vida de barrio, aspectos fundamentales que permiten valorar los avances o retrocesos en estos procesos de lucha. Por esta razón, dentro de los hitos más importantes que los dirigentes destacan del proceso, mencionan la ocupación efectiva de tierras, la construcción de distintas obras, la legalización de la tenencia de la tierra, y la entrega de las escrituras de propiedad. El proceso mismo es evaluado en función de las transformaciones efectivas que se logran en el territorio y del progresivo acceso a los servicios básicos y acceso a derechos sociales. La praxis de lucha colectiva, que transforma el territorio en lugar, es 
posible gracias a la articulación de fuerzas sociales que derivan de las familias y de su tradición cultural de lucha.

En relación con la historicidad, se puede observar cómo los barrios son el resultado de la agrupación de personas que provienen de múltiples provincias del país, por lo cual se puede considerar que constituyen territorio-lugares de diversidad cultural, lo que se contrapone con otros actores institucionales (tanto públicos como privados) con quienes se desarrollan importantes antagonismos durante los procesos, y quienes aparecen como actores que encarnan una perspectiva monocultural dominante. A su vez, dentro de los hitos más importantes que los dirigentes destacan del proceso, mencionan el reconocimiento de su organización y de su lucha por parte de las autoridades, lo que refuerza la propia conciencia popular y la valoración de su lucha. En este sentido, en el nombre de los barrios se destacan significados asociados al origen mismo del lugar o al proceso de conquista popular que antecedió a la construcción de barrio. Sin embargo, se observa cómo a través del tiempo disminuye progresivamente el interés por celebrar el aniversario del barrio o por generar espacios de integración comunitaria, apareciendo un progresivo interés por generar espacios de integración y celebración de fiestas comunitarias articuladas a festividades religiosas, navidad, fin de año o fiestas de Quito. Esto podría dar cuenta de un proceso por medio del cual la historia local y la memoria social del proceso de lucha, se integran/articulan en las historias y memorias de la ciudad. En relación con los factores psicosociales, que median la producción de territorialidad e historicidad, identificamos:

A) El rol del dirigente: la persona del dirigente resulta fundamental como mediador entre la percepción de la injusticia social a la base de la experiencia cotidiana de carencias vitales, y la activación de los recursos y potencialidades populares para luchar contra estas injusticias. A la vez, estos dirigentes deben asumir una importante carga y desgaste 
emocional asociada a los conflictos internos (por poca experiencia, machismo, desconfianzas, y violencia, entre otros) y externos (trámites burocráticos, incumplimiento de compromisos institucionales, alargamiento de los plazos y tiempos, entre otros), constituyéndose en los actores principales que dinamizan/activan la lucha popular.

B) La conciencia popular: esta conciencia popular se relaciona con sentimientos de indignación frente a la exclusión social que vivencian a diario, sobre todo frente a la percepción de una baja preocupación institucional por las personas pobres, así como también por malas prácticas de los propios dirigentes y organizaciones populares. Esta conciencia popular opera como una dimensión que refuerza y valora el camino de la lucha popular, como vía principal para el logro de sus reivindicaciones históricas.

C) La organización social: considerada como el mecanismo principal para materializar la 'unión comunitaria', como un valor central de estas luchas, lo que les permitiría alcanzar las metas colectivas, desde una actitud de exigibilidad de derechos, a la vez que fortalecer los vínculos y relaciones sociales. Es decir, la organización aparece como la vía para afrontar los problemas y necesidades, en la perspectiva de luchar por una vida digna, por medio de la solidaridad, reciprocidad y apoyo mutuo.

Finalmente podemos decir que estas luchas urbanas transitan por un complejo campo de tensiones/problemas/necesidades, en cuyo contexto la valoración del proceso depende principalmente de los logros materiales y del reconocimiento obtenido, lo que lleva a resaltar las potencialidades de la lucha popular para la producción social del hábitat.

\section{Discusiones sobre el concepto de comunidad: homogeneidad/consenso versus heterogeneidad/conflicto}

Ahora estamos en condiciones de discutir ciertas limitaciones conceptuales de la categoría "comunidad", que se usa como fundamento del quehacer en Psicología Social 
Comunitaria. Vemos que se tensionan dos perspectivas o énfasis frente al concepto de comunidad: homogeneidad/consenso versus heterogeneidad/conflicto.

La unidad que supone la "comunidad" no opera como homogeneidad experiencial, si no que se reproduce, más bien, como movimientos de actualización permanente de lo que se connota como "comunidad", en cuanto uso del término por parte de los grupos sociales. Nos referimos a la necesidad de mostrar "hacia fuera y hacia dentro" una cierta identidad y unidad de fuerzas que nunca es total, pero que es necesaria para la consolidación y proyecciones de la lucha. Este uso popular del término comunidad, en función de las prácticas sociales observadas, se estructura a partir del esfuerzo constante de superación de las contradicciones internas que se observan en la dimensión conflictiva de las relaciones comunitarias e institucionales. Se deben superar, integrar o apaciguar las diferencias culturales, la confrontación de valores asociados a una forma de gestión popular, de actitudes inadecuadas para el proceso de participación, y de discusión sobre las estrategias más efectivas para las reivindicaciones sociales. Tal conflictividad permanente se va resolviendo en la medida en que se amplifican las opciones de diálogo, debate y consenso social, y sobre todo en la recuperación permanente de la memoria colectiva de los grupos organizados, que fortalece el sentido de identidad social.

Los movimientos urbano-populares que hemos explorado no necesariamente se fundan o tienen un territorio compartido, lo producen y reproducen a partir de los patrones de apropiación que predominan, según las relaciones de fuerzas que operan en ese proceso, pero que varía conforme las coyunturas se resuelven. Los movimientos son inherentemente historia en movimiento, porque justamente son sujetos históricos que se constituyen como sujetos colectivos que protagonizan una reivindicación legítima, y que evidencian las contradicciones de las estructuras institucionales opresoras. El territorio (espacio) y la historia (tiempo) se articulan como unidad ontológica, por lo que no hay "un" 
territorio compartido, ya que los grupos sociales contienen formas de territorialización que se definieron en historias anteriores de habitar, y que permanecen en cierta medida cuando migran y luchan para la conformación de los nuevos barrios populares que hemos observado. Queremos decir con esto que hay una yuxtaposición de territorialidades que se reconfiguran por la praxis misma de la lucha y la apropiación del espacio urbano. Hablar de un territorio común sería pensar que el territorio es un contenedor de relaciones sociales comunes, sin entender que la propia territorialidad implica relaciones de fuerza, de poder e identificación simbólica con los lugares, que no es regular, que es históricamente producida, y que se transforma permanentemente dado el carácter progresivo o regresivo de su consolidación. El proceso simbólico de identificación con el lugar, asociado a la territorialidad y la historicidad, no puede ser un proceso cuasi mecánico entre territorio (contenedor) y significaciones asociadas a él (sujeto). Esto no permite explicar los procesos de re-identificación con los lugares en tanto movimiento asociado a coyunturas específicas, y los cambios en los significados y sentidos ligados a las dinámicas extremadamente fluctuantes que se viven y sufren en las luchas por-ellugar.

La interacción social o el tipo de interacción o vínculo social "positivo" no puede entenderse sino a través del conjunto de relaciones de interacción que las personas viven en cuanto se mueven por la ciudad y sus instituciones sociales, desde donde son socializados, bajo la posibilidad de reproducir las ideologías dominantes 0 de transformarlas en otra visiones de mundo, y que están relacionadas con valores e intereses contenidos en los modelos de ciudad que circulan en la esfera pública. Es complejo pensar en esta dimensión cuando hay trayectorias históricas diferenciadas en términos sociales y culturales. Las valoraciones de las interacciones no pueden homogenizarse cuando el encuentro y relación intercultural supone varios tipos de 
interacción posible, en términos de ampliación, integración o confrontación de las diferencias. De hecho es el propio espectro de posibilidades que están contenidos en las sabidurías populares y los aprendizajes acumulados por generaciones en los grupos sociales, que van creando y actualizando en los espacios de diálogo colectivo de las asambleas populares.

La idea de cultura común, necesaria para la conformación de comunidad, nos parece limitada. Sobre todo cuando observamos una compleja red de relaciones interculturales, en donde no se construyen de manera general significados compartidos. Estos son parciales según la orientación y situación de la acción, lo cual también genera dificultades por los sentidos y valoraciones que han sido construidas en los espacios sociales de vida de las personas. Hay más bien una diversificación permanente de los significados que, en tanto movimiento de la lucha, varían dependiendo de las situaciones conflictivas que hacen redefinir acciones y significados. Esto lo observamos en la diversidad cultural y diversidad de lugares que constituyen una nueva territorialidad a partir de la diferenciación. La inducción de la lucha, es decir el objetivo común se funda en una necesidad común, pero no en una cultura común. Es más, lo común es la homogenización normativa de las posibilidades de producción del espacio urbano, contenida en la institucionalidad del Estado y los gobiernos de las ciudades, que es externa a la heterogeneidad cultural contenida en los movimientos urbano-populares. Las nociones de orden espacial son puestas en entredicho cuando no es posible congraciar dignidad de vida con normativa y legislación urbana, ni menos con la heterogeneidad cultural predominante. Es ahí donde las contradicciones emergen como parte del proceso de mercantilización de la ciudad, en contraposición a una ciudad construida por sus propios hacedores, que buscan horizontes de vida, justicia social y dignidad. 
Las pertenencias o formas de "pertenecer a" o "sentirse parte de" no sólo se limita a compartir valores o propósitos que se actualizan en la interacción social. La noción de pueblo o de pobre, por ejemplo, implicaría una pertenencia a un grupo social que se caracteriza por vivir bajo condiciones de precariedad y exclusión social. Si puede haber una pertenencia previa entre personas que no se conocen y que no generan acciones conjuntas. Cuando las personas se vinculan, en este caso para luchar por el derecho a la vivienda y al hábitat, la pertenencia previa presupone la pertenencia del grupo de lucha. Es la propia historia de exclusión estructural lo que genera una cierta pertenencia asociada a las condiciones de vida y a la experiencia común de despojo que se vive en los sectores populares. Es a partir de la conciencia popular, la organización social y el rol de la dirigencia popular, que estas condiciones estructurales se articulan y operan como formas de pertenencia definida por las condiciones de exclusión, explotación y subalternidad.

La potencialidad de un grupo social organizado no se define por sus características internas. Esta lógica de pensar hacia dentro es muy característica en la PSC, pues el sentido de comunidad aparece cuando observamos atributos propios del grupo. Sin embargo, y como observamos en nuestras análisis, la definición de la acción de la lucha está siempre constreñida por las estructuras jurídicas, económicas y sociales, que van a ser determinantes en la noción de la comunidad. Esta se define en relación con las posibilidades y problemas que se le presentan con otras comunidades, sean burocráticas, políticas, del mismo pueblo por disputas horizontales por el territorio. La afirmación de sí sólo se entenderá, a través de la afirmación que otros hacen sobre tal afirmación de sí, dado que es el encuentro y tensión con los grupos instituidos lo que define en gran medida las prácticas sociales, que en definitiva dan cuenta del contenido específico de lo que es una comunidad, en tanto potencialidad social. 


\section{Conclusiones}

El amplio debate interdisciplinar que intenta establecer marcos comprensivos en torno a la compleja relación entre personas, grupos y espacios construidos, sigue siendo un problema de investigación teórico-metodológico central. Este estudio buscó explorar las experiencias y voces de los y las protagonistas que impulsaron procesos históricos y multidimensionales de lucha por-el-lugar, en la construcción y consolidación de barrios populares en la ciudad de Quito. Para esto optamos por un diálogo conceptual entre las categorías "comunidad, territorialidad e historicidad", para ampliar marcos compresivos sobre una realidad específica, la de la producción del hábitat popular, identificando limitaciones en las orientaciones sobre comunidad ampliamente usadas en la PSC.

En este sentido, la perspectiva de historicidad y territorialidad nos permite ampliar los contornos del debate en relación con la noción de comunidad. Estas dimensiones dan cuenta de la articulación dinámica y permanente entre territorio e historia, entre los lugares que habitamos y las memorias que nos habitan. Es problemático construir una definición universalmente válida y socialmente pertinente de la comunidad, ya que esta se expresaría, al mismo tiempo, como proceso y como resultado, es decir, como movimiento y devenir de un grupo humano situado en/desde diferentes lugares e historias. Por otro lado, creemos que estas dimensiones también nos permiten situar estas luchas populares en el contexto más amplio de las luchas sociales y políticas que, desde las fronteras y grietas del sistema, se enfrentan al capitalismo dominante y sus graves efectos para la sostenibilidad y re-producción de la vida, lo que amplía los horizontes de la transformación social posible y deseable para nuestra disciplina.

Concluimos que hay un déficit teórico importante en la PSC, la que se construye principalmente a partir de categorías descriptivas tendientes a la homogenización de los fenómenos. Esta cuestión trae el importante desafío de revitalizar el corpus de 
conocimientos existentes en la región, y capturar la diversidad y complejidad de formas de apropiación social y territorial.

\section{Referencias}

Almeida, E. \& Sánchez, M. (2014). Comunidad. Interacción, conflicto y utopía. Puebla: Universidad Iberoamericana Puebla.

Berroeta, H. (2014). El quehacer de la psicología comunitaria: coordenadas para una cartografía. Psicoperspectivas. Individuo y Sociedad. 14(2), 19-31.

González, T., Aguilera, A. \& Torres, A. (2013). Investigar subjetividades y formación de sujetos en y con organizaciones y movimientos sociales. En C. Piedrahita, A. Díaz y P. Vommaro. Acercamientos metodológicos a la subjetivación política: debates latino-americanos. Bogotá: CLACSO.

Grondona-Opazo, G. \& Rodríguez, M. (2017). Lucha popular por-el-lugar en la periferia urbana de Quito: Reflexiones críticas desde/sobre la Psicología Social Comunitaria. Revista Eureka, M(2), 67-93.

Jariego, M. (2004). Sentido de comunidad y potenciación comunitaria. Apuntes de Psicología, 22(2), 187-211.

Krause Jacob, M. (2001). Hacia una redefinición del concepto de comunidad -cuatro ejes para un análisis crítico y una propuesta. Revista de Psicología, X (2), 49-60.

Lefebvre, H. (1976). Espacio y política, el derecho a la ciudad II. Barcelona: Ediciones Península.

Montero, M. (2004). Introducción a la psicología comunitaria. Desarrollo, conceptos y procesos. Buenos Aires: Paidós.

Musitu, G., Herrera, J., Cantera, L., \& Montenegro, M. (2004). Introducción a la psicología comunitaria. Barcelona: Editorial UOC. 
Porto-Gonçalves, C. (2009). De saberes y de territorios: diversidad y emancipación a partir de la experiencia latino-americana. Polis, 8(22), 121-36.

Retamozo, M. (2006). Esbozos para una epistemología de los sujetos y movimientos sociales. Cinta de Moebio, (26), 207-18.

Rodríguez, A. (2012). Aportes a de la Psicología Comunitaria al campo de las políticas públicas sociales: el caso del Uruguay. En J. Alfaro, A. Sánchez, y A. Zambrano (Eds.), Psicología Comunitaria y Políticas Públicas: reflexiones y experiencias (pp. 111-146). Buenos Aires: Paidós.

Rodríguez, M. (2013) El patrón de acumulación neoliberal: fragmentación y exclusión socio-territorial en América Latina. Revista Electrónica de Psicología Política, 11(31), 1-21.

Rodríguez, M., Grondona-Opazo, G., Erazo, J. \& Festjens, J. (2016). Disputas urbanopopulares: creatividad y antagonismos para la construcción de barrios del Buen Vivir en Quito, Ecuador. En P. Abramo, M. Rodríguez y J. Erazo, Ciudades populares en disputa ¿Acceso a suelo urbano para todos? (pp. 33-65). Quito: Editorial Universitaria Abya-Yala-UPS-Universidad Federal de Río de JaneiroCLACSO.

Rodríguez, A., \& Montenegro, M. (2016). Retos Contemporáneos para la Psicología Comunitaria: Reflexiones sobre la Noción de Comunidad. Revista Interamericana de Psicologia/Interamerican Journal of Psychology (IJP), 50(1), 14-22.

Sánchez Vidal, A. (2009). Validación discriminante de una escala de sentimiento de comunidad: análisis comparativo de dos comunidades. International Journal of Psychology and Psychological Therapy, 9(2), 161-176.

Segato, R. (2007). La nación y sus otros. Raza, etnicidad y diversidad religiosa en tiempos de políticas de la identidad. Buenos Aires: Prometeo Libros. 
Toro, Z. (2012). Territorio-lugar: espacio de resistencia y lucha de los movimientos sociales. Pacarina del Sur, 3(11). Recuperado de: http://pacarinadelsur.com/home/abordajes-y-contiendas/421-territorio-lugarespacio-de-resistencia-y-lucha-de-los-movimientos-sociales

Wiesenfeld, E. (2016). Trascendiendo confines disciplinares: continuidad, psicología comunitaria crítica y psicología social comunitaria al revés. Revista Interamericana de Psicología/Interamerican Journal of Psychology (IJP). 50(1), 4-13.

Wiesenfeld, E. (1994). La psicología ambiental en el contexto de la comunidad: Hacia una Psicología Ambiental Comunitaria. Psicología Contemporánea, 7(2), 40-49.

Winkler M. I., Alvear, K., Olivares, B. \& Pasmanik, D. (2009). Autonomía V/S dependencia. Quehacer comunitario y políticas públicas. Santiago: Usach.

Zemelman, H. (2012). Subjetividad y realidad social. En C. Piedrahita, Á. Díaz, y P. Vommaro (Eds.), Subjetividades políticas: desafíos y debates latinoamericanos (pp. 235-246). Bogotá: Universidad Distrital Francisco José de Caldas.

Zibechi, R. (2003). Los movimientos sociales latinoamericanos: tendencias y desafíos. OSAL : Observatorio Social de América Latina, 9.

Zibechi, R. (2007). Autonomías y emancipaciones. América Latina en movimiento. Lima: Programa Democracia y Transformación Global - Fondo Editorial de la Facultad de Ciencias Sociales UNMSM. 
Formato de citación

Rodríguez-Mancilla, M., Grondona-Opazo, G. (2018). Luchas urbanas en barrios populares de la ciudad de Quito: territorialidad e historicidad desde las voces de sus protagonistas. Psicología, Conocimiento y Sociedad, 8(1), 117-143. doi: http://dx.doi.org/10.26864/PCS.v8.n1.6 